\title{
Psychoanalytisches zum Humor
}

\section{Alexander Wildbolz}

Dr. med., Facharzt für Psychiatrie und Psychotherapie, Mitglied FMH, Ausbildungsanalytiker der Schweizerischen Gesellschaft für Psychoanalyse

Ich habe den in der SÄZ erschienenen Artikel von Ursula Steiner-König über das Lachen sehr genossen und finde die Idee unseres Zentralvorstandes, den Humor als Thema für den Tag der Kranken 2016 zu wählen, ausgezeichnet. Das inspiriert mich als Psychoanalytiker zu einigen Bemerkungen über Lachen, Witz, Humor und Komik.

\section{Kleine Geschichte des Lachens}

Eine kleine, vorwiegend abendländische Geschichte des Lachens verdanken wir Georges Minois: Heiteres Lachen war in der Antike den Göttern vorbehalten. Im alten Ägypten brachte die Göttin Maat ihre Lebenslust und ihren Kampf gegen die Macht des Todes mit Lachen zum Ausdruck. Bei den Griechen war es Dionysos, der auch das satirische Drama leitete; die ihm gewidmeten Bauernfeste standen nach Aristoteles am

\section{Humor ist eine Kultur und Religion übergreifende allgemein menschliche Fähigkeit.}

Ursprung der Komödie. Aristophanes wird als Erbe betrachtet; seine niemanden verschonenden Werke erzeugen ein aggressives, ironisches Lachen, mit dem Ziel, die soziale Ordnung zu bewahren. Der Gegensatz dazu ist das liebliche Lachen, wie es durch die Komödien des Menandros ausgelöst wird. Das sokratische Lachen wiederum steht für eine Ironie im Dienste der Weisheit. Der Syrer Lukian von Samosata lachte nach der Devise "Alles vergehen lassen, nichts ernst nehmen»; er war das Schreckgespenst aller Dogmatiker, und die ersten Christen sahen in ihm die Verkörperung des Teufels. Petronius («Satiricon») ist der grösste Künstler des grotesken Genres, dessen bitteres Lachen

Inspiré par l'article de Ursula Steiner-König sur l'effet bénéfique du rire paru dans le Bulletin des médecins suisses et par l'idée du Comité central de choisir l'humour comme thème pour la Journée des malades 2016, I'auteur résume brièvement I'histoire du rire selon Georges Minois pour ensuite passer à quelques remarques psychanalytiques et à la contribution de Sigmund Freud. die Konsequenz einer Periode von Terror und Bürgerkrieg ist. Mit Cicero («De oratore») wird das Lachen verknüpft mit dem Wortspiel zu einer Waffe, mit der man den Feind besiegt. Im Mittelalter konnte sich dem Heiligen das Weltliche lustvoll-ironisch überlagern, wie der Satz von Caesarius von Heisterbach zeigen mag: «Herr, wenn Du mich nicht von der Versuchung befreist, werde ich mich bei Deiner Mutter beklagen!» Der Narr war im Mittelalter eine wichtige Figur, dessen durch weise Verrücktheit charakterisierte Scherze die Wahrheit der Höfe denunzierten Kinder und Narren sprechen die Wahrheit, wobei der Narr aber nicht naiv ist. Und zu gewissen Zeiten erlaubte die Kirche Volksfeste, wie den Karneval, der erstmals 1294 in Nizza stattgefunden haben soll. In der Periode der Französischen Revolution wird das Lachen zynisch, aggressiv; ein Beispiel dafür ist ein Tanz aus der Provence, die Farandole, in welcher das betäubende Lachen Gewalt, Angst und Tod bekämpft. Im 19. Jh. kritisiert Hegel die Ironie; das Lachen als Antisystem passt nicht in seine Philosophie, nach welcher «alles Reale rational und alles Rationale real» ist. Kierkegaard hingegen ist Ironie und Humor gegenüber positiv gesinnt, aber in einem sokratischen Sinn als Übergang vom Unnützen zum Ethischen, zu Gott schliesslich. Nach Schopenhauer ist das Lachen Ausdruck der plötzlichen Wahrnehmung einer Inkongruenz; es verbindet wahrgenommene mit gedachter Realität. In der Sturm-und-Drang-Zeit wird erneut Erhabenes und Närrisches vermischt; Jean Paul unterscheidet klassisches, moralisierendes, prosaisches und subversives Lachen. Victor Hugo beschreibt das Lachen der Generationen des 19. Jh., die das Schwinden der Idealisierungen und die Konfrontation mit einem desorientierenden Positivismus erleben mussten. Für Bergson schliesslich ist das Lachen eine Art soziale 


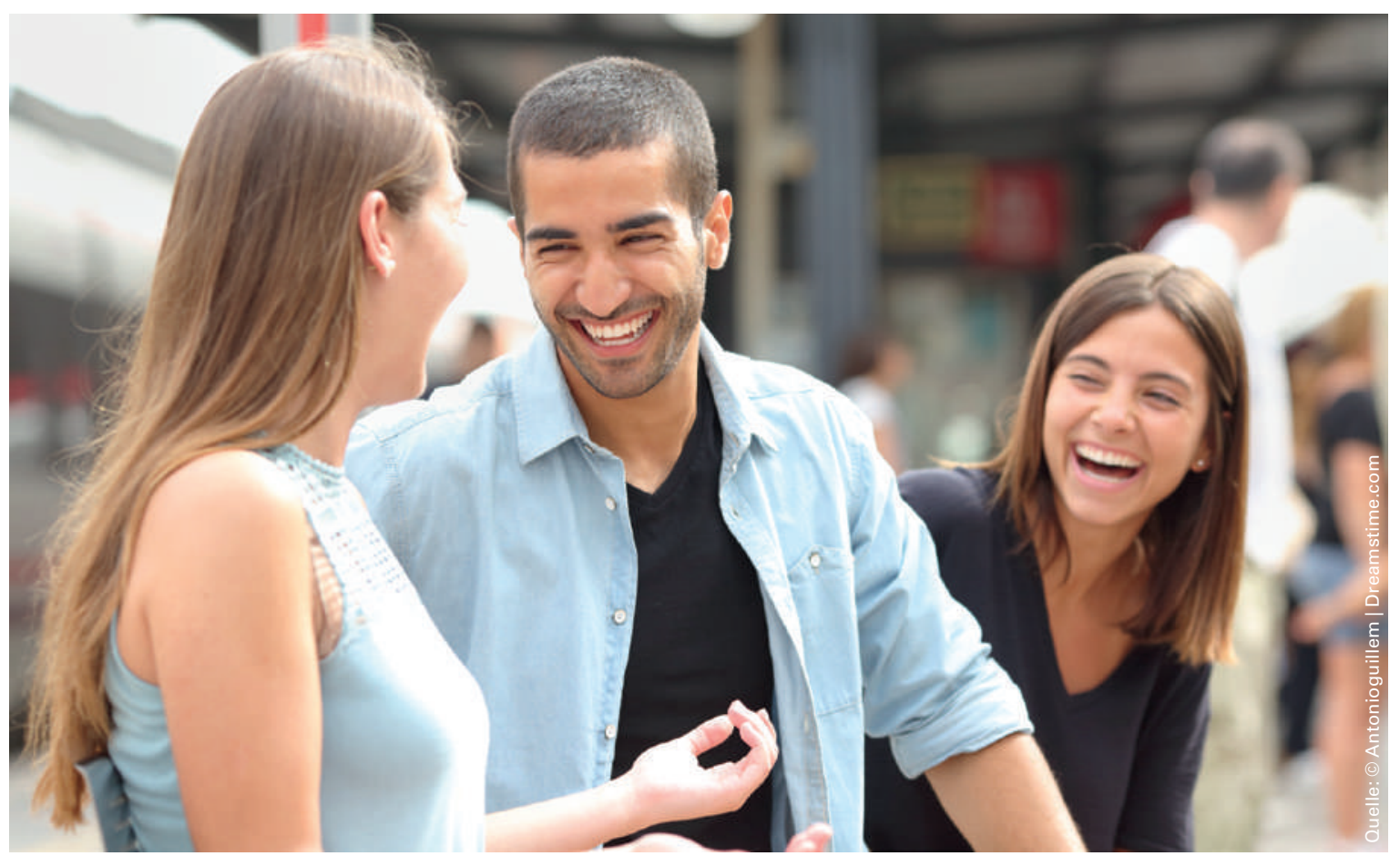

Laut Freud führen Witz, Humor und Komik zu einer im Lachen zum Ausdruck kommenden, auf einer Ersparung beruhenden lustvollen Erregungsabfuhr über bestimmte Muskelgruppen.

Geste, die ein die Kohäsion der Gruppe potentiell bedrohliches Verhalten stigmatisiert.

\section{Humor hat, wer trotzdem lacht}

Humor ist eine Kultur und Religion übergreifende allgemein menschliche Fähigkeit. Er verbindet, relativiert, lockert auf. Sein Gegenteil ist der exzessive Ernst, den man tödlich nennt. Der tödliche Ernst ist absolut humorlos.

Der Humor erleichtert interkulturelle Begegnungen, wenn er den Andern respektiert, ihn nicht beleidigt. Er hat Platz in der psychoanalytischen Sitzung.

Gibt es humorvolle Träume? Natürlich, Humor kommt auch im Traum vor. Traum und Witz haben gewisse Ähnlichkeiten. Beide sind deutbar. Traum- und Witzarbeit operieren mit ähnlichen Mechanismen wie Verschiebung und Verdichtung. Aber Träume sind asozial, wenden sich primär nur an den Träumenden. Der Witz hingegen ist ein ausgesprochen soziales Phänomen, er muss erzählt werden.

\section{Freuds Beitrag}

Sigmund Freud war zwar auch ein Kind des Abendlandes, aber er hatte ein grosses Interesse für das kulturübergreifende, allgemein menschliche Psychische. Seine Beiträge zum Humor haben ihre Allgemeingül- tigkeit bis heute bewahrt. Grundsätzlich Menschliches ist überall sehr ähnlich, wie unterschiedlich gefärbt es im lokalen Einzelnen daherkommen mag.

Judenwitze, die der Jude Freud ohne Rassismusverdacht erzählen konnte, finden sich in seinem ganzen Werk. Es gibt sie bereits in der «Traumdeutung», dann besonders zahlreich in «Der Witz und seine Beziehung zum Unbewussten" und in "Der Humor».

Freud unterscheidet Witz, Humor und Komik, die in zahlreichen Unterkategorien vorkommen und oft untereinander Verbindungen eingehen. Haben diese drei prinzipiellen Arbeitsweisen unseres seelischen Apparates etwas Gemeinsames? Nun, alle drei führen zu einer im Lachen zum Ausdruck kommenden lustvollen Erregungsabfuhr über bestimmte Muskelgruppen.

\section{Traum und Witz haben gewisse Ähnlichkeiten.}

Aber worauf beruht diese lustvolle Erregungsabfuhr? Nach Freud beruht sie auf einer Ersparung.

Beim Witz geht die Lust aus erspartem Hemmungsaufwand hervor.

Zwei Juden treffen in der Nähe des Badehauses zusammen. «Hast du genommen ein Bad?», fragt der eine. "Wieso?», fragt der andere dagegen, "fehlt eins?»

Das ist ein Wortwitz, der auf dem Doppelsinn des Wortes «nehmen» und auf Verschiebung beruht. Bei der 
Frage liegt der Akzent auf «Bad», bei der witzigen Antwort auf «nehmen» im Sinne von wegnehmen. Die witzige Antwort hat den Sinn der Frage auf einen Nebensinn verschoben. Der ersparte Hemmungsaufwand zeigt sich in der Plötzlichkeit, mit der wir von der hemmenden Erwartung einer seriösen sinngemässen Antwort befreit werden. Blitzschnell erkennen wir einen andern Sinn im scheinbaren Unsinn, was sich kathartisch im Lachen entlädt.

Beim Humor geht die Lust aus erspartem Gefühlsaufwand hervor.

Der Spitzbube, der am Montag zur Exekution geführt wird, äussert: «Na, diese Woche fängt gut an.»

Dieses Beispiel des gröbsten Falles von Humor, des Galgenhumors, ist, wie Freud uns dazu sagt, eigentlich ein Witz, ist doch die Bemerkung an sich zutreffend, aber in ganz unsinniger Weise deplatziert, verschoben, weil es ja für den hingerichteten «Spitzbuben" gar keine weiteren Ereignisse dieser Woche geben wird. Aber es gehört Humor dazu, einen solchen Witz zu machen, Humor, der sich in einer bewundernswerten Gelassenheit über das gegenwärtige Unglück erhebt, der bis zuletzt trotzig den persönlichen Narzissmus, das Lustprinzip hochhält. Der für den Protagonisten wie für uns ersparte Gefühlsaufwand liegt in der verachtenden Verleugnung jeglicher Gefühle von Verzweiflung, Mitleid, wie sie doch der Situation eigentlich angemessen wären. Im Humor zeigt sich ein gegenüber dem eingeschüchterten Ich liebevoll-tröstlich eingestelltes Überich, ganz entsprechend seiner Abkunft von der ja nicht nur verbietenden Elterninstanz.

Bei der Komik stammt die Lust aus erspartem Vorstellungsaufwand.

Für ein kleines Mädchen wird eine "Französin" als Gouvernante aufgenommen, deren Person aber nicht seinen Beifall findet. Kaum dass die neu Engagierte sich entfernt hat, lässt die Kleine ihre Kritik verlauten: «Das soll eine Französin sein! Vielleicht heisst sie sich so, weil sie einmal bei einem Franzosen gelegen ist!»

Freud sagt dazu, dass das sogar ein erträglicher Witz sein könnte, Doppelsinn mit Zweideutigkeit. Aber es ist in diesem Fall ein Ausdruck kindlicher Naivität, da die Kleine keine Ahnung hatte von der Möglichkeit des Doppelsinns; sie hatte nur eine oft gehörte scherzhafte Behauptung der Unechtheit auf die ihr unsympathische Fremde übertragen: «Das soll echtes Gold sein?
Das ist vielleicht einmal bei Gold gelegen!» Weil wir Erwachsenen aber die Zweideutigkeit sofort erkennen und geniessen, ist diese Situation für uns komisch, im Unterschied zum kleinen naiven Mädchen, das unser Lachen nicht versteht. Dieses Beispiel mag die Stellung des Naiven zwischen dem Witz und dem Komischen erläutern. Der ersparte Vorstellungs- oder Besetzungsaufwand liegt im Vergleich, hier dem Vergleich des Kindlichen mit dem Erwachsenen; wir müssen uns gar nicht mehr weiter in das Kindliche hineinversetzen, können blitzartig ausweichen in unsere Erwachsenenwelt. Es ist Bedingung für die Entstehung des Komischen, dass wir veranlasst werden, gleichzeitig oder in rascher Aufeinanderfolge für die gleiche Vorstellungsleistung zweierlei verschiedene Vorstellungsweisen anzuwenden, zwischen denen dann die «Vergleichung" stattfindet, aus welcher sich die komische Differenz ergibt. Solche Aufwanddifferenzen entstehen

\section{Der Humor erleichtert interkulturelle Begeg- nungen, wenn er den Andern respektiert und ihn nicht beleidigt.}

z.B. zwischen dem Fremden und dem Eigenen, dem Gewohnten und dem Veränderten, dem Erwarteten und dem Eingetroffenen (Erwartungskomik). Das Komische muss entdeckt, kann aber auch gemacht werden denken wir an Chaplins zeitlose Figur des Tramps.

Am Schluss seiner Arbeit über den Witz sagt Freud sehr schön über Witz, Humor und Komik: «... alle drei kommen darin überein, dass sie Methoden darstellen, um aus der seelischen Tätigkeit eine Lust wiederzugewinnen, welche eigentlich erst durch die Entwicklung dieser Tätigkeit verloren gegangen ist. Denn die Euphorie, welche wir auf diesen Wegen zu erreichen streben, ist nichts anderes als die Stimmung einer Lebenszeit, in welcher wir unsere psychische Arbeit überhaupt mit geringerem Aufwand zu bestreiten pflegten, die Stimmung unserer Kindheit, in der wir das Komische nicht kannten, des Witzes nicht fähig waren und den Humor nicht brauchten, um uns im Leben glücklich zu fühlen.»

\footnotetext{
Literatur:

- Freud S. Traumdeutung, 1900, GW II/III

- Freud S. Der Witz und seine Beziehung zum Unbewussten, 1905, GW VI

- Freud S. Der Humor, 1927, GW XIV

- Minois, G. Storia del riso e della derisione, 2004, Dedalo

- Steiner-König, U. Lachen verbindet, ist ansteckend, schenkt Glücksmomente. Schweiz Ärztezeitung. 2016;97(8):275-6.
} 